\title{
A nasobiliary drain connected to a waterjet system to facilitate endoscopic ultra- sound-guided gastrojejunostomy
}

Gastric outlet obstruction (GOO) reduces quality of life and compromises nutrition. Duodenal stenting is the first-line treatment but does not completely relieve symptoms. Surgical gastrojejunostomy improves the quality of life in patients who are expected to survive for a long time. In patients with benign conditions such as chronic pancreatitis, duodenal stents are ineffective (being associated with high migration rates), and surgical gastrojejunostomy is both difficult and risky because of the significant malnutrition and frequent portal hypertension attributable to portosplenic thromboses. Recently, endoscopic ultrasound (EUS)-guided gastrojejunostomy using electrocautery to place a lumenapposing metal stent has emerged as a new minimally invasive procedure.

Three techniques have been reported [1]: the single-balloon-occluded technique [2], double-balloon-occluded gastrojejunostomy bypass [3] (EPASS), and a direct technique [4]. The latter is the most attractive technique but is associated with the risk of puncture of an empty jejunum. Here, we report a case treated via direct EUS-guided gastrojejunostomy using a nasobiliary drain connected to a waterjet system.

A 55-year-old man with GOO secondary to chronic pancreatitis and portal vein thrombosis was hospitalized in our gastroenterology unit ( $\triangleright$ Fig. 1). Surgical gastrojejunostomy was contraindicated because of massive portal hypertension; we thus performed EUS-guided gastrojejunostomy ( $\triangleright$ Video 1$)$.

The first step featured dilation of the stenosis to allow a nasobiliary drain to be placed in the jejunum ( $\triangleright$ Fig. 2). The drain was connected to a waterjet system, which allowed continuous jejunal filling with normal saline containing small amounts of a carmine coloring agent and contrast ( $\triangleright$ Fig. 3). A therapeutic echoendoscope was inserted into the stomach, parallel to the nasobiliary drain. Constant

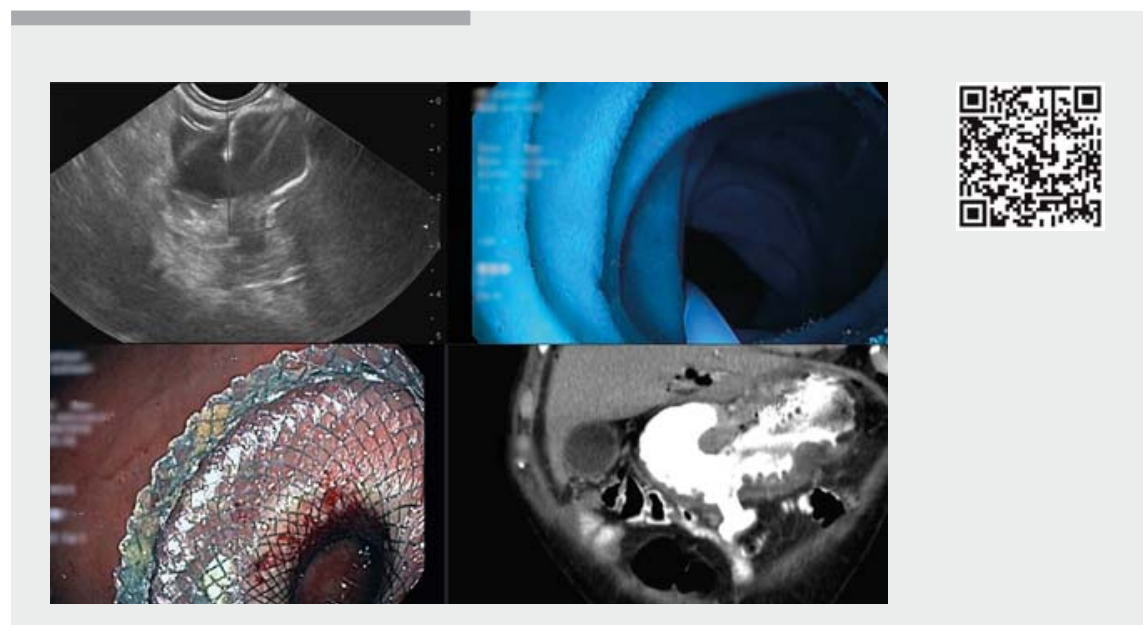

Video 1 Gastrojejunostomy using nasobiliary drain and lumen-apposing metal stent.

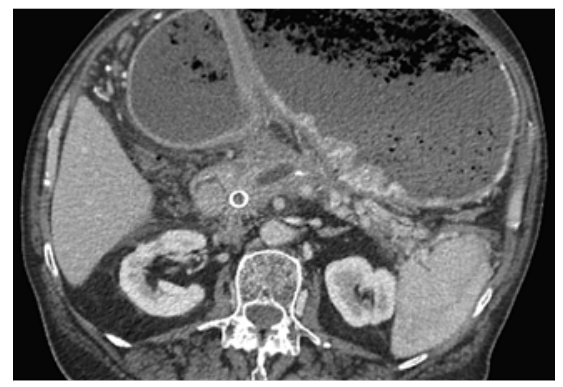

- Fig. 1 Gastric outlet obstruction due to chronic pancreatitis.

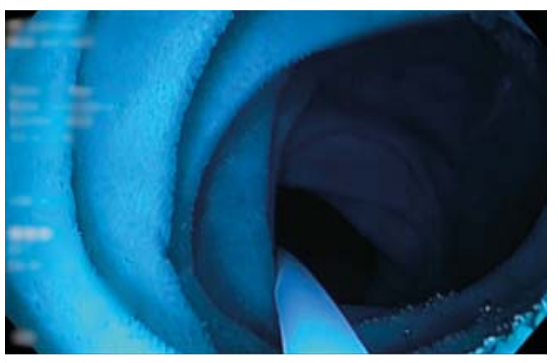

Fig. 3 Filling of the jejunal loop with carmine-colored normal saline.

filling of the jejunum by the waterjet facilitated clear visualization of the dilated jejunum and performance of direct EUSguided gastrojejunostomy using a HOT AXIOS device (Boston Scientific, Marlbor-

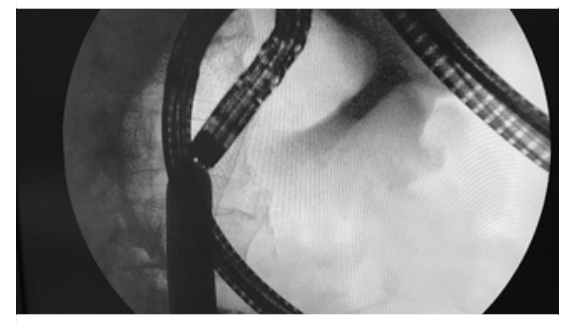

Fig. 2 Dilation of the duodenal stenosis.

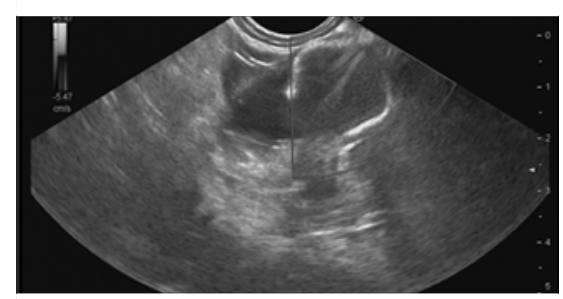

- Fig. 4 Opening of the distal flange of the lumen-apposing metal stent.

ough, Massachusetts, USA) with diameter of $20 \mathrm{~mm}$ ( $\triangleright$ Fig. 4, $\triangleright$ Fig. 5, $\triangleright$ Fig. 6). One day later, food was successfully taken, and the patient was discharged the next day. Thus, the use of a nasobili- 


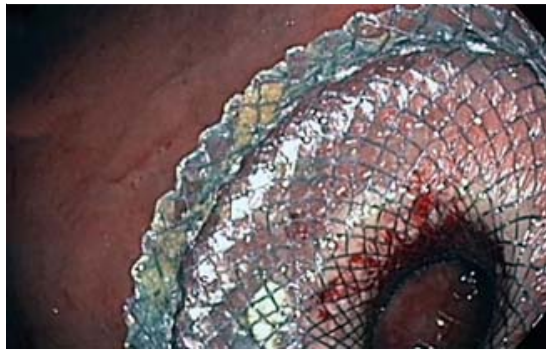

Fig. 5 Endoscopic view of the gastrojejunostomy.

ary drain connected to a waterjet system is a simple way to facilitate direct EUSguided gastrojejunostomy via constant filling of the target jejunum.

Endoscopy_UCTN_Code_TTT_1AS_2AG

\section{Competing interests}

Dr. Jacques has been a speaker for Boston Scientifics.

The authors

Marion Schaefer ${ }^{1,2}$, Abdelkader Taibi ${ }^{3}$, Hugo Lepetit $^{2}$, Romain Legros ${ }^{2}$, Sylvaine DurandFontanier ${ }^{3}$, Mathieu Pioche ${ }^{4}$, Jérémie Jacques $^{2,5}$

1 Service d'Hépato-gastroentérologie, $\mathrm{CHU}$ de Nancy, Vandoeuvre-lès-Nancy, France

2 Service d'Hépato-gastroentérologie, $\mathrm{CHU}$ Dupuytren, Limoges, France

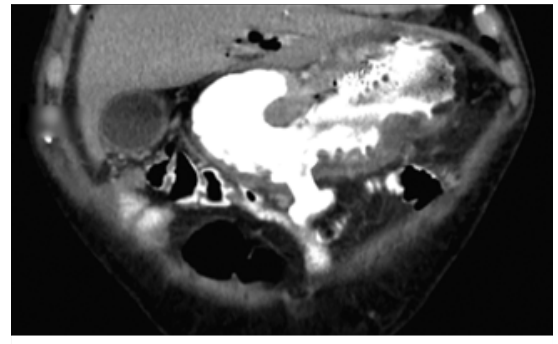

> Fig. 6 Coronal computed tomography view of the gastrojejunostomy with contrast ingestion.

3 Service de Chirurgie Digestive et Endocrinienne, CHU Dupuytren, Limoges, France

4 Service d'Hépato-gastroentérologie, Hôpital Edouard Herriot, CHU Lyon, France

5 BioEM, XLim, UMR 7252, CNRS, Limoges, France

\section{Corresponding author}

\section{Marion Schaefer, MD}

Service d'hépato-gastro-entérologie, $\mathrm{CHU}$ de Nancy, Rue du Morvan, 54500

Vandoeuvre-lès-Nancy, France

Fax: +33-3-83153633

mrn.schaefer@gmail.com

\section{References}

[1] Itoi T, Baron TH, Khashab MA et al. Technical review of endoscopic ultrasonographyguided gastroenterostomy in 2017. Dig Endosc 2017; 29: 495 - 502
[2] Tyberg A, Perez-Miranda M, Sanchez-Ocaña $R$ et al. Endoscopic ultrasound-guided gastrojejunostomy with a lumen-apposing metal stent: a multicenter, international experience. Endosc Int Open 2016; 4: E276-E281

[3] Itoi T, Ishii K, Ikeuchi N et al. Prospective evaluation of endoscopic ultrasonographyguided double-balloon-occluded gastrojejunostomy bypass (EPASS) for malignant gastric outlet obstruction. Gut 2016; 65: 193 195

[4] Khashab MA, Kumbhari V, Grimm IS et al. EUS-guided gastroenterostomy: the first U.S. clinical experience (with video). Gastrointest Endosc 2015; 82: 932 - 938

\section{Bibliography}

DOI https://doi.org/10.1055/a-0862-0183

Published online: 1.4.2019

Endoscopy 2019; 51: E158-E159

(c) Georg Thieme Verlag KG

Stuttgart · New York

ISSN 0013-726X

\section{ENDOSCOPY E-VIDEOS}

https:/|eref.thieme.de/e-videos

Endoscopy E-Videos is a free access online section, reporting 靣转: on interesting cases and new

techniques in gastroenterological endoscopy. All papers include a high quality video and all contributions are freely accessible online.

This section has its own submission website at https://mc.manuscriptcentral.com/e-videos 